\title{
Article \\ Systemic Inflammation and the Breakdown of Intestinal Homeostasis Are Key Events in Chronic Spinal Cord Injury Patients
}

\author{
David Diaz ${ }^{1,2,3}$, Elisa Lopez-Dolado ${ }^{1,4} \mathbb{D}^{\mathbb{D}}$, Sergio Haro ${ }^{1,2}$, Jorge Monserrat 1,2,3 $\mathbb{D}^{\mathbb{D}}$, Carlos Martinez-Alonso ${ }^{5}$, \\ Dimitrios Balomeros 5 , Agustín Albillos 1,2,3,6 and Melchor Alvarez-Mon 1,2,3,7,*
}

1 Department of Medicine, University of Alcalá, Crta N-II km 33.6, Alcalá de Henares, 28871 Madrid, Spain; david.diaz@uah.es (D.D.); lamidolado@gmail.com (E.L.-D.); sergioharogiron@gmail.com (S.H.); Jorge.monserrat@uah.es (J.M.); Agustin.albillos@uah.es (A.A.)

2 Institute Ramón y Cajal for Health Research (IRYCIS), Ctra. Colmenar Viejo, 28034 Madrid, Spain

3 Biomedical Institute for Liver and Gut Diseases (CIBEREHD), Instituto de Salud Carlos III, Av. Monforte de Lemos, 3-5, 28029 Madrid, Spain

4 Service of Rehabilitation, National Hospital for Paraplegic Patients, Carr. de la Peraleda, S/N, 45004 Toledo, Spain

5 Department of Immunology and Oncology, Universidad Autónoma de Madrid, Calle Darwin, 3, 28049 Madrid, Spain; cmartineza@cnb.csic.es (C.M.-A.); dbalomenos@cnb.csic.es (D.B.)

6 Service of Gastroenterology, University Hospital Ramón y Cajal, 28034 Madrid, Spain

7 Immune System Diseases and Oncology Service, University Hospital "Príncipe de Asturias", Crta N-II km 33.6, Alcalá de Henares, 28871 Madrid, Spain

* Correspondence: mademons@gmail.com; Tel.: +34-1-885-4533; Fax: +34-1-885-4526

\section{check for}

updates

Citation: Diaz, D.; Lopez-Dolado, E.; Haro, S.; Monserrat, J.;

Martinez-Alonso, C.; Balomeros, D.; Albillos, A.; Alvarez-Mon, M.

Systemic Inflammation and the Breakdown of Intestinal Homeostasis Are Key Events in Chronic Spinal Cord Injury Patients. Int. J. Mol. Sci. 2021, 22, 744. https://doi.org/ 10.3390/ijms22020744

Received: 20 November 2020 Accepted: 10 January 2021 Published: 13 January 2021

Publisher's Note: MDPI stays neutral with regard to jurisdictional clai$\mathrm{ms}$ in published maps and institutional affiliations.

Copyright: (C) 2021 by the authors. Licensee MDPI, Basel, Switzerland. This article is an open access article distributed under the terms and conditions of the Creative Commons Attribution (CC BY) license (https:// creativecommons.org/licenses/by/ $4.0 /)$.

\begin{abstract}
Our aim was to investigate the subset distribution and function of circulating monocytes, proinflammatory cytokine levels, gut barrier damage, and bacterial translocation in chronic spinal cord injury (SCI) patients. Thus, 56 SCI patients and 28 healthy donors were studied. The levels of circulating CD14 ${ }^{\text {high }} \mathrm{CD} 16^{-}, \mathrm{CD} 14^{+ \text {high }} \mathrm{CD} 16^{+}$, and $\mathrm{CD} 14^{+ \text {low }} \mathrm{CD} 16^{+}$monocytes, membrane TLR2, TLR4, and TLR9, phagocytic activity, ROS generation, and intracytoplasmic TNF- $\alpha$, IL-1, IL-6, and IL-10 after lipopolysaccharide (LPS) stimulation were analyzed by polychromatic flow cytometry. Serum TNF- $\alpha$, IL-1, IL-6 and IL-10 levels were measured by Luminex and LPS-binding protein (LBP), intestinal fatty acid-binding protein (I-FABP) and zonulin by ELISA. SCI patients had normal monocyte counts and subset distribution. $\mathrm{CD} 14^{\text {+high }} \mathrm{CD} 16^{-}$and $\mathrm{CD} 14^{\text {+high }} \mathrm{CD} 16^{+}$monocytes exhibited decreased TLR4, normal TLR2 and increased TLR9 expression. CD14 ${ }^{\text {high }}$ CD16 ${ }^{-}$monocytes had increased LPS-induced TNF- $\alpha$ but normal IL-1, IL-6, and IL-10 production. Monocytes exhibited defective phagocytosis but normal ROS production. Patients had enhanced serum TNF- $\alpha$ and IL6 levels, normal IL-1 and IL-10 levels, and increased circulating LBP, I-FABP, and zonulin levels. Chronic SCI patients displayed impaired circulating monocyte function. These patients exhibited a systemic proinflammatory state characterized by enhanced serum TNF- $\alpha$ and IL- 6 levels. These patients also had increased bacterial translocation and gut barrier damage.
\end{abstract}

Keywords: monocyte; cytokines; chronic spinal cord injury; bacterial translocation; gut barrier damage; systemic inflammation

\section{Introduction}

Spinal cord injury (SCI) is a cause of severe health problems and disability [1]. The acute stage of the disease is characterized by the induction of a neurological lesion of the spinal cord and the associated clinical manifestations and systemic stress responses determined by the etiopathogenesis of the SCI [2-7]. The management of acute SCI has improved in recent years, with a dramatic reduction in mortality $[8,9]$. However, patients with chronic SCI suffer a high incidence of medical complications, such as infections, metabolic diseases, cardiovascular events, and recurrent episodes of impaired general health [10,11]. 
It is well known that acute SCI patients show an intense disturbance of immuneinflammatory responses, which includes hallmarks of inflammation and immunodeficiency $[12,13]$. At injury sites in the spinal cord, the infiltration of immune cells, including monocytes/macrophages, is involved in determining the extent of the initial tissue damage and causing secondary neural destruction during the first several weeks postinjury [2,14]. Furthermore, the secondary systemic immunodepression that is observed in patients with SCI has been associated with a predisposition to infection complications $[15,16]$. Acute inflammation after SCI also appears to be related to patient functional outcomes [17]. The mechanisms that contribute to acute SCI-associated immune disturbance appear to be multifactorial, including traumatic and surgery stress-related neuro-endocrine responses, infection complications, and central and autonomous nervous system alterations and lesions [18,19].

The function of the immune system in patients with chronic SCI remains partially characterized. Abnormal levels of several circulating cytokines have been described [20]. Decreased natural killer (NK) cell counts and cytotoxic activity levels have been reported, and T lymphocytes from patients with chronic SCI also show abnormal function $[6,21]$. Furthermore, inflammatory cells have been detected in human spinal cord tissue years after the initial SCI [22].

Monocytes are bone marrow-derived cells that mediate essential regulatory and effector functions in innate and adaptative immunity [23]. Circulating human monocytes are phenotypically and functionally heterogeneous and are divided into three major subsets based on the expression of the lipopolysaccharide (LPS) receptor CD14 and the Fc $\gamma$ RIII lowaffinity IgG receptor $\mathrm{CD} 16$ : classical $\left(\mathrm{CD} 14^{\text {thigh }} \mathrm{CD} 16^{-}\right)$, intermediate $\left(\mathrm{CD} 14^{\text {thigh }} \mathrm{CD} 16^{+}\right)$, and nonclassical $\left(\mathrm{CD} 14^{+ \text {low }} \mathrm{CD} 16^{+}\right)[23,24]$.

The recognition of microorganisms by proteins that recognize pathogen-associated molecular patterns, such as Toll-like receptors (TLRs), is critical for the activation of monocytes and development of the natural immune response [25]. TLR2, TLR4, and TLR9 recognize bacterial molecules, such as lipoteichoic acid, LPS, and unmethylated cytosinephosphate-guanine DNA, respectively. Activated monocytes show relevant immunomodulatory activities, including the secretion of pivotal cytokines, such as the proinflammatory cytokines interleukin (IL)-6, IL-1 and tumor necrosis factor-alpha (TNF- $\alpha$ ), and the antiinflammatory cytokine IL-10 [26]. Monocytes are also important phagocytic cells [27]. Monocytes have been demonstrated to be involved in the pathogenesis of several organspecific and systemic inflammatory diseases [28].

In experimental models of SCI, intestinal dysbiosis and increased gut permeability were recently demonstrated [29]. We propose that patients with chronic SCI suffer damage to the intestinal barrier, with secondary increased permeability that favors increased bacterial translocation, and a systemic inflammatory imbalance, with monocyte compromise. Intestinal fatty acid-binding protein (I-FABP) and zonulin are recognized protein markers of the integrity of the intestinal barrier. The hepatic synthesis of LPS-binding protein is promoted by LPS [30], and in several clinical settings, plasma LBP reflects long-term exposure to bacteria and their endotoxins [31,32].

We have focused our work on the study of circulating monocytes and the level of bacterial translocation and gut barrier damage in patients with chronic SCI. To avoid confounding factors, we focused our study on a homogeneous population of 56 chronic SCI patients without clinical infections or concomitant diseases with potential interactions with the immune system. In parallel, we studied 28 age- and sex-matched healthy controls (HCs). We analyzed the pattern of distribution of the $\mathrm{CD} 14^{+ \text {high }} \mathrm{CD} 16^{-}, \mathrm{CD} 14^{\text {thigh }} \mathrm{CD} 16^{+}$ and $\mathrm{CD} 14^{+ \text {low }} \mathrm{CD} 16^{+}$circulating monocyte subsets, as well as their TLR2, TLR4 and TLR9 expression levels. We also investigated the intracytoplasmic production of TNF- $\alpha$, IL-1, IL-6 and IL-10 after LPS stimulation and the serum levels of these cytokines. Monocyte reactive oxygen species (ROS) production and phagocytic activity were also analyzed. We measured the serum levels of LBP, I-FABP, and zonulin to study bacterial translocation and gut barrier damage. 


\section{Results}

\subsection{Demographic Profile of Chronic SCI Patients}

Table 1 shows the characteristics of the 56 chronic SCI patients and 28 HCs included in the analysis. No significant differences were found between chronic SCI patients and HCs with respect to age or sex distribution or the clinical and analytical variables studied.

Table 1. Demographic, clinical and biological data of the patients and healthy controls.

\begin{tabular}{|c|c|c|c|c|c|c|}
\hline Variables & Healthy Controls & Chronic SCI & AIS Group 1 & AIS Group 2 & $\begin{array}{l}\text { Injury Level } \\
\text { Group } 1\end{array}$ & $\begin{array}{c}\text { Injury Level } \\
\text { Group } 2\end{array}$ \\
\hline & $(n=28)$ & $\begin{array}{l}\text { Patients } \\
(n=55)\end{array}$ & $\begin{array}{c}(\mathrm{A}-\mathrm{B}) \\
(n=30)\end{array}$ & $\begin{array}{l}(\mathrm{C}-\mathrm{D}) \\
(n=25)\end{array}$ & $\begin{array}{l}(\mathrm{C} 1-\mathrm{T} 6) \\
(n=35)\end{array}$ & $\begin{array}{l}(\mathrm{T} 7-\mathrm{L} 6) \\
(n=20)\end{array}$ \\
\hline Age (years) & $25.03 \pm 2.86$ & $26.92 \pm 12.87$ & $24.96 \pm 12.90$ & $30.65 \pm 13.30$ & $23.28 \pm 13.64$ & $27.21 \pm 12.69$ \\
\hline $\begin{array}{c}\text { Sex } \\
(\operatorname{men} \% / \text { women } \%)\end{array}$ & $43.24 / 56.76$ & $68.00 / 32.00$ & $76.67 / 23.33$ & $60.86 / 39.14$ & $74.28 / 25.71$ & $57.89 / 42.10$ \\
\hline $\begin{array}{l}\text { Time of injury } \\
\text { (years) } \\
\text { AIS }(\%)\end{array}$ & & $12.00 \pm 9.22$ & $10.7 \pm 9.15$ & $12.91 \pm 9.61$ & $10.74 \pm 9.69$ & $14.23 \pm 8.81$ \\
\hline A & & 34.00 & 63.33 & & 48.57 & 10.52 \\
\hline B & & 21.43 & 36.67 & & 14.28 & 26.31 \\
\hline $\mathrm{C}$ & & 19.64 & & 45.83 & 8.57 & 36.84 \\
\hline $\mathrm{D}$ & & 25.00 & & 54.17 & 28.57 & 21.05 \\
\hline \multicolumn{7}{|l|}{ Injury level (\%) } \\
\hline $\mathrm{C} 1-\mathrm{C} 4$ & & 23.21 & 20.00 & 25.00 & 34.28 & \\
\hline $\mathrm{C} 5-\mathrm{C} 8$ & & 19.64 & 20.00 & 16.67 & 28.57 & \\
\hline T1-T6 & & 23.22 & 33.33 & 12.50 & 37.14 & \\
\hline T7-T12 & & 19.64 & 13.33 & 29.17 & & 57.89 \\
\hline L1-L6 & & 14.29 & 13.33 & 16.67 & & 42.10 \\
\hline
\end{tabular}

AIS: American Spinal Injury Association (ASIA) Impairment Scale; SCI: Spinal Cord Injury.

At the inclusion time, $68 \%$ of the SCI patients were males and $32 \%$ women. Their mean age was $26.9286 \pm 12.8797$ years. The mean time of SCI onset was $11.6786 \pm 9.0621$ years, a time of evolution that certainly define them as chronic injuries. Regarding the SCI etiology, 54\% were traumatic (traffic accidents, diving injuries and falls), and the rest of them non-traumatic, 5\% birth-SCI doubt to labor dystocia, $11 \%$ inflammatory myelitis, $6 \%$ spinal vascular diseases, $11 \%$ spinal cord tumor sequelae, and the remaining $13 \%$ consequently to spina bifida.

Regarding the need for spinal surgery in the acute period of SCI, it was necessary in $76 \%$ of traumatic patients versus $56 \%$ of those whose injury was due to a non-traumatic aetiology. Traumatic patients mainly received vertebral fracture reduction and arthrodesis by plates or bars and screws. Only one of them required replacement of the osteosynthesis material a few weeks after the first surgery, due to loosening and incomplete reduction of the fracture. Non-traumatic patients were treated by laminectomies and drainage of abscesses or haematomas or, in the case of spina bifida, closure of the congenital spinal defect at birth. No statistically significant differences were found between both subgroups in this regard (Mann-Whitney Rank Sum Test, $p=0.134$ ). Only $12 \%$ of the traumatic patients needed new spinal surgeries along their SCI time evolution, compared to $45 \%$ of the non-traumatic ones (Mann-Whitney Rank Sum Test, $p=0.001$ ), mostly due to the need of an average of more than two spinal surgeries in the SB patients. In no case was any patient included in the study who had undergone surgery, spinal or any other type, in the last year. The average time since the last surgery in the present series was 3.6 years, being significantly longer in non-traumatic cases (Mann-Whitney Rank Sum Test, $p=0.016$ ).

The neurological level of spinal damage was located within C1-C4, C5-C8, T1-T6, T7-T12 and lumbosacral metameras in $23.21 \%, 19.64 \%, 23.22 \%, 19.64 \%$ and $14.29 \%$ of the patients respectively, which implies that more than $66 \%$ of our patients showed SCI above T6, with higher expected signs and symptoms of autonomic disreflexia. With respect to the ASIA impairment score (AIS), 34\% of the patients were AIS A, 21.43\% AIS B, 19.64\% AIS C, 
and $25 \%$ AIS D, meaning that although $66 \%$ of our patients showed incomplete lesions, only $44.64 \%$ showed motor incomplete injuries with different degrees of infralesional motor preservation and theoretically better mobility profiles. These results are in agreement with the quite good functional scores that these patients reached, both in the basic activities of daily living and in the ability to walk: the mean SCIM III score of our series was $60 \pm 2.9818$ over a maximum score of 100 . When we analyzed the three SCIM III domains separately, we found acceptable performance in self-care (mean subscore $=14.5 \pm 0.8886$ over a maximum of 20), respiratory and sphincters management (mean score $=26.0714 \pm 0.8816$ over a maximum of 40) and mobility (mean subscore $=19.4464 \pm 1.5289$ over a maximum of 30). Locomotion was preserved in 32 patients, (mean WISCI II score of $12.1875 \pm 1.1798$ over a maximum value of 20), meaning of $57 \%$ of our patient series. It would be a quite surprising result, since we only had $44.64 \%$ motor incomplete injuries in our series and plus $66 \%$ of them showed SCI above T6, in which locomotion is less less likely to be preserved. A value of 12 in WISCI II scale implies to walk with two crutches plus both legs braces and no physical assistance throughout $10 \mathrm{~m}$, which is more a therapeutic than community locomotion, not able to free the patient from the wheelchair (Thomas Jefferson University. Copyright 2004). Regarding another neurological consequences of having a chronic SCI, our patients showed mild-moderate levels of spasticity (mean Ashworth and Penn scores, $1.4821 \pm 0.1372$ and $1.5536 \pm 0.1650$ respectively) and pain (mean basal nociceptive and neuropathic VAS score $=0.3214 \pm 0.1198$ and $0.9107 \pm 0.2474$ respectively; mean VAS score during pain nociceptive and neuropathic crisis $=0.3214 \pm 0.1198$ and $0.9107 \pm 0.2474$ respectively). Finally, to ensure that only neurologically stable patients were recruited, a magnetic resonance scan and sensory and motor evoked potentials were performed, excluding from the present study those patients who, in the opinion of the radiologist and/or neurophysiologist, were worse than in previous studies. In the MRI images, the presence of syringomyelia was specifically addressed as an evolutionary complication in both traumatic and non-traumatic patients. Only $0.02 \%$ and $0.18 \%$ of our cases respectively presented it at the radiologist's discretion. Only those syringomyelia that had not been modified in the last year were included.

The deficits derived from the autonomic nervous system damage were evident in the bladder (mean bladder ASIA Autonomic Standard Assessment score $=2.6250 \pm 0.2016$ over a maximum value of 6) and bowel (mean Bowel ASIA Autonomic Standard Assessment score $=2.5357 \pm 0.2101$ ) function of our patients, but although they suffered an average of less than 2 UTIs in the previous year, a higher rate than the general population (Flores-Mirelles et al., 2015; Foxman et al., 2000), no urinary or intestinal relevant complication was reported. With regard to the comorbidity conditions, the patients of our series showed non significative levels of fatigue (mean FSS scale $=2.3988 \pm 0.1985$ ) and only mild levels of anxiety (mean anxiety HAD score $=5.9464 \pm 0.5568$; mean anxiety EADG score $=2.7321 \pm 0.3852$ ) and depression (mean depression HAD score $=3.4107 \pm 0.5082$; mean depression EADG score $=2.0357 \pm 0.3293$ ). No statistically significant differences were found between traumatic and non-traumatic patients regarding to these parameters. No significant differences were found either between SCI patients and healthy controls with respect to age or sex distribution, neither in the clinical nor analytical variables studied except in two points: the comorbidity was significatively higher (mean SCI patients Charlson score $=2.7679 \pm 0.1299$ versus controls $=0.0909 \pm 0.290 ; p<0.001$ ) and the One's own health status perception significatively lower (mean SCI EQ5D-VAS score $=68.8929 \pm 3.3782$ versus controls $=84.975 \pm 1.358 ; p<0.001$ ) between SCI patients and healthy controls, pointing to the intense impact that a chronic SCI, even the less complicated of them, has in a patient's life.

\subsection{Chronic SCI Patients Show Normal Monocyte Subset Distributions and Cell Counts but Abnormal TLR Expression}

First, we studied the absolute number of circulating monocytes and their percentages in PBMCs from 56 patients with chronic SCI and 28 sex- and age-matched HCs. There were no statistically significant differences in the number of circulating mono- 
cytes between SCI subjects and HCs (Figure 1a). Next, we studied the distribution of the $\mathrm{CD} 14^{\text {+high }} \mathrm{CD} 16^{-}, \mathrm{CD} 14^{\text {thigh }} \mathrm{CD} 16^{+}$and $\mathrm{CD} 14^{\text {+low }} \mathrm{CD} 16^{+}$monocyte subsets in both groups of subjects (Figure 1). There were no significant differences in the percentages of the $\mathrm{CD} 14^{\text {+high }} \mathrm{CD} 16^{-}, \mathrm{CD} 14^{\text {+high }} \mathrm{CD} 16^{+}$and $\mathrm{CD} 14^{+ \text {low }} \mathrm{CD} 16^{+}$monocyte subsets in the circulating monocyte population between chronic SCI patients and HCs.
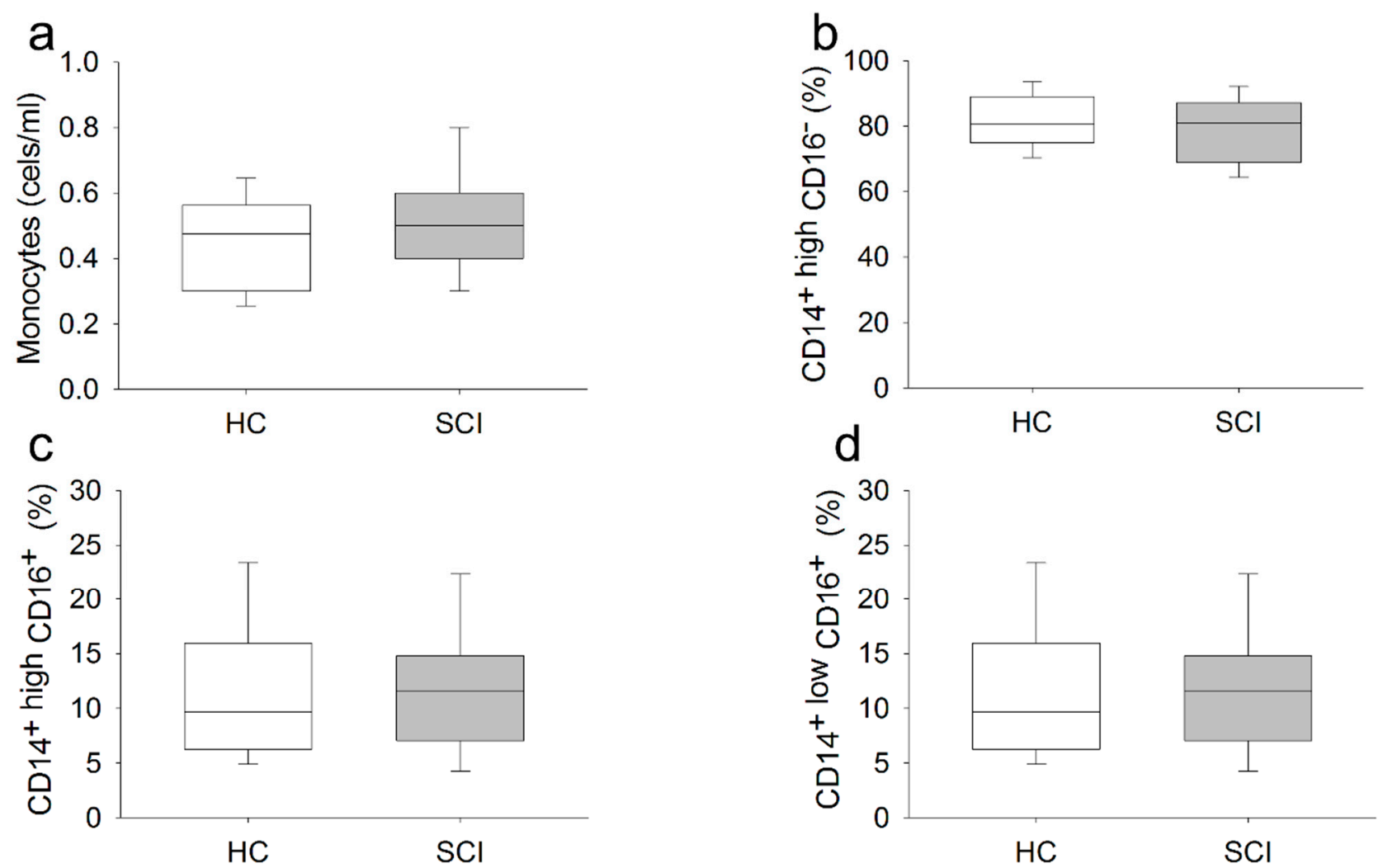

Figure 1. Absolute number of circulating monocytes and the distribution of monocyte subsets in chronic SCI patients. Absolute number (cells $/ \mu \mathrm{L}$ ) of circulating monocytes: (a) and the percentages of the $\mathrm{CD} 14^{+ \text {high }} \mathrm{CD} 16^{-} ;(\mathbf{b}) \mathrm{CD} 14^{+ \text {high }} \mathrm{CD} 16^{+}$; (c) and $\mathrm{CD} 14^{+ \text {low }} \mathrm{CD}^{+} 6^{+}$; (d) monocyte subsets in chronic SCI patients (gray box) and healthy controls (white box).

We also investigated the expression of TLR2, TLR4 and TLR9 in circulating monocytes from both groups of subjects (Figure 2). We found a significant decrease in the percentage of circulating monocytes that expressed TLR4 in patients with chronic SCI compared to the percentage observed in HCs. Concomitant with that change, we observed a significant increase in the percentage of monocytes that expressed TLR9 in SCI patients compared to the percentage observed in HCs. In contrast, we found no significant differences in the percentage of monocytes that expressed TLR2. We also analyzed TLR4, TLR9 and TLR2 expression in the different monocyte subsets from chronic SCI patients and HCs. We found a significant decrease in the percentages of the $\mathrm{CD} 14^{+ \text {high }} \mathrm{CD} 16^{-}$and $\mathrm{CD} 14^{\text {+high }} \mathrm{CD} 16^{+}$monocyte subsets that expressed TLR4 in SCI patients compared to the percentages observed in HCs. In contrast, we observed significant increases in the percentages of $\mathrm{CD} 14^{\text {+high }} \mathrm{CD} 16^{-}$and $\mathrm{CD} 14^{\text {thigh }} \mathrm{CD} 16^{+}$monocytes that expressed TLR9 in SCI patients compared to the percentages observed in HCs. No differences in the expression of TLR2 in the CD14 ${ }^{\text {thigh }} \mathrm{CD} 16^{-}$, $\mathrm{CD} 14^{\text {thigh }} \mathrm{CD} 16^{+}$, and $\mathrm{CD} 14^{+ \text {low }} \mathrm{CD} 16^{+}$monocyte subsets were observed between the two groups of subjects. 

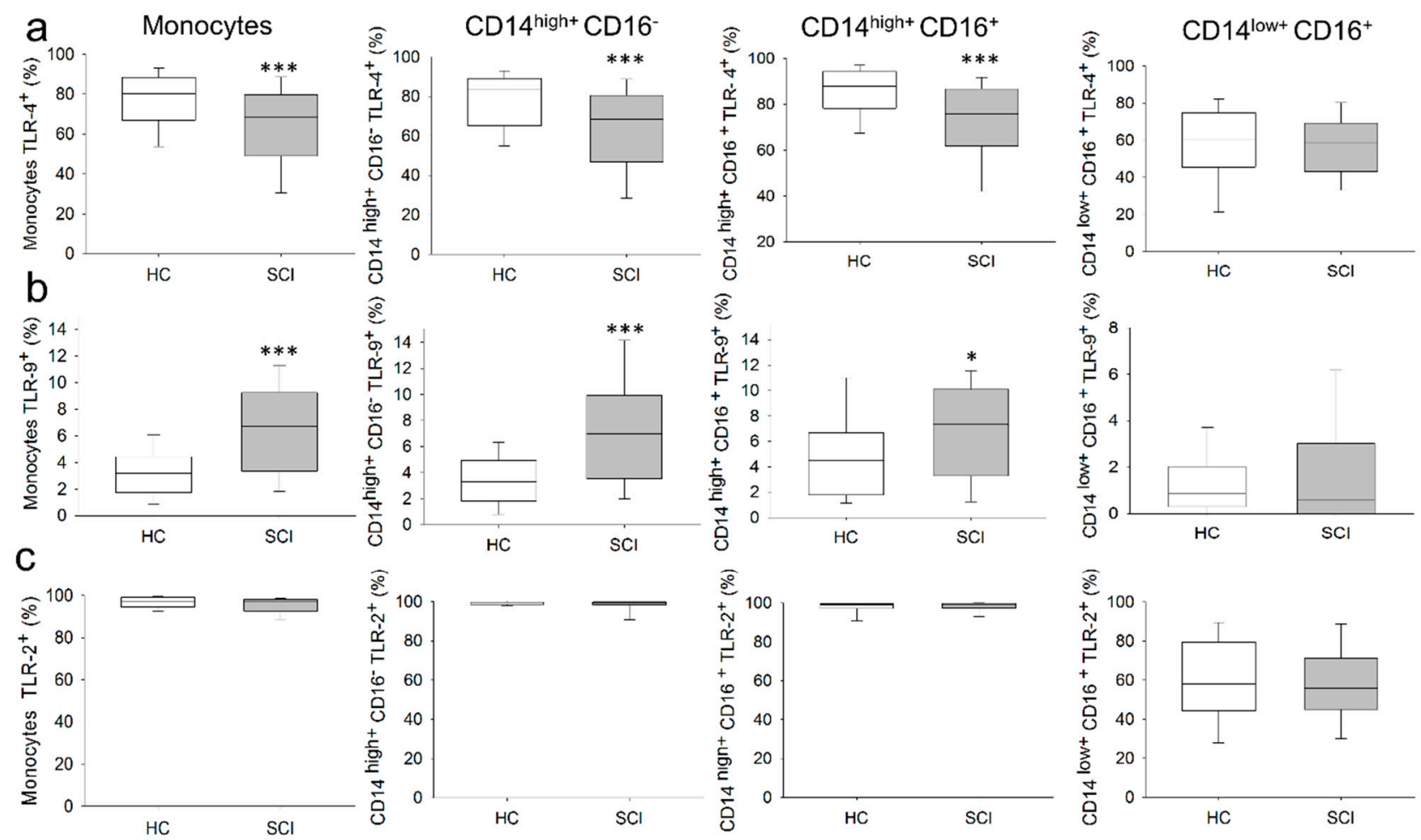

Figure 2. Expression of TLR4, TLR9 and TLR2 in circulating monocyte subsets from chronic SCI patients. Percentages of TLR4: (a) TLR9; (b) and TLR2; (c) in circulating monocytes and the CD14 ${ }^{\text {thigh }} \mathrm{CD} 16^{-}, \mathrm{CD} 14^{+ \text {high }} \mathrm{CD} 16^{+}$and $\mathrm{CD} 14^{+ \text {low }} \mathrm{CD} 16^{+}$ monocyte subsets from chronic SCI patients (gray box) and healthy controls (white box). * Significant difference between patients and healthy controls $(p<0.05) .{ }^{* *}$ Significant difference between patients and healthy controls $(p<0.001)$.

\subsection{Chronic SCI Patients Exhibit TNF- $\alpha$ Overproduction by Monocytes and Increased Serum Levels of the Proinflammatory Cytokines TNF- $\alpha$ and IL-6}

The intracellular expression of TNF- $\alpha$, IL-1 $\beta$, IL- 6 and IL-10 was analyzed in monocytes from SCI patients and HCs after LPS stimulation (Figure 3). We found a significant increase in the percentage of monocytes that produced TNF- $\alpha$ after LPS stimulation in chronic SCI patients compared to the percentage observed in HCs. We found no significant differences in the percentages of monocytes that expressed IL-1 $\beta$, IL-6, and IL-10 between the two groups of subjects.

Next, we studied the expression of these cytokines in the $\mathrm{CD} 14^{+ \text {high }} \mathrm{CD} 16^{-}, \mathrm{CD} 14^{+ \text {high }}$ $\mathrm{CD} 16^{+}$and $\mathrm{CD} 14^{+ \text {low }} \mathrm{CD} 16^{+}$monocyte subsets after LPS stimulation. We found that the $\mathrm{CD} 14^{+ \text {high }} \mathrm{CD} 16^{-}$monocyte subset from chronic SCI patients shows increased TNF- $\alpha$ expression compared to the expression level of the same subset in HCs. In contrast, in the three analyzed monocyte subsets, there were no significant differences in the percentages of monocytes that expressed IL-1 $\beta$, IL-6, and IL-10 after LPS stimulation between the two groups of subjects.

We also measured the circulating levels of the proinflammatory cytokines TNF- $\alpha$, IL-1 $\beta$ and IL- 6 and the anti-inflammatory cytokine IL-10 (Figure 4). Subjects with chronic SCI had significantly higher levels of TNF- $\alpha$ and IL- 6 than did HCs. Most chronic SCI patients presented higher TNF- $\alpha$ levels $(70.83 \%)$ than did the top quartile of HCs. 

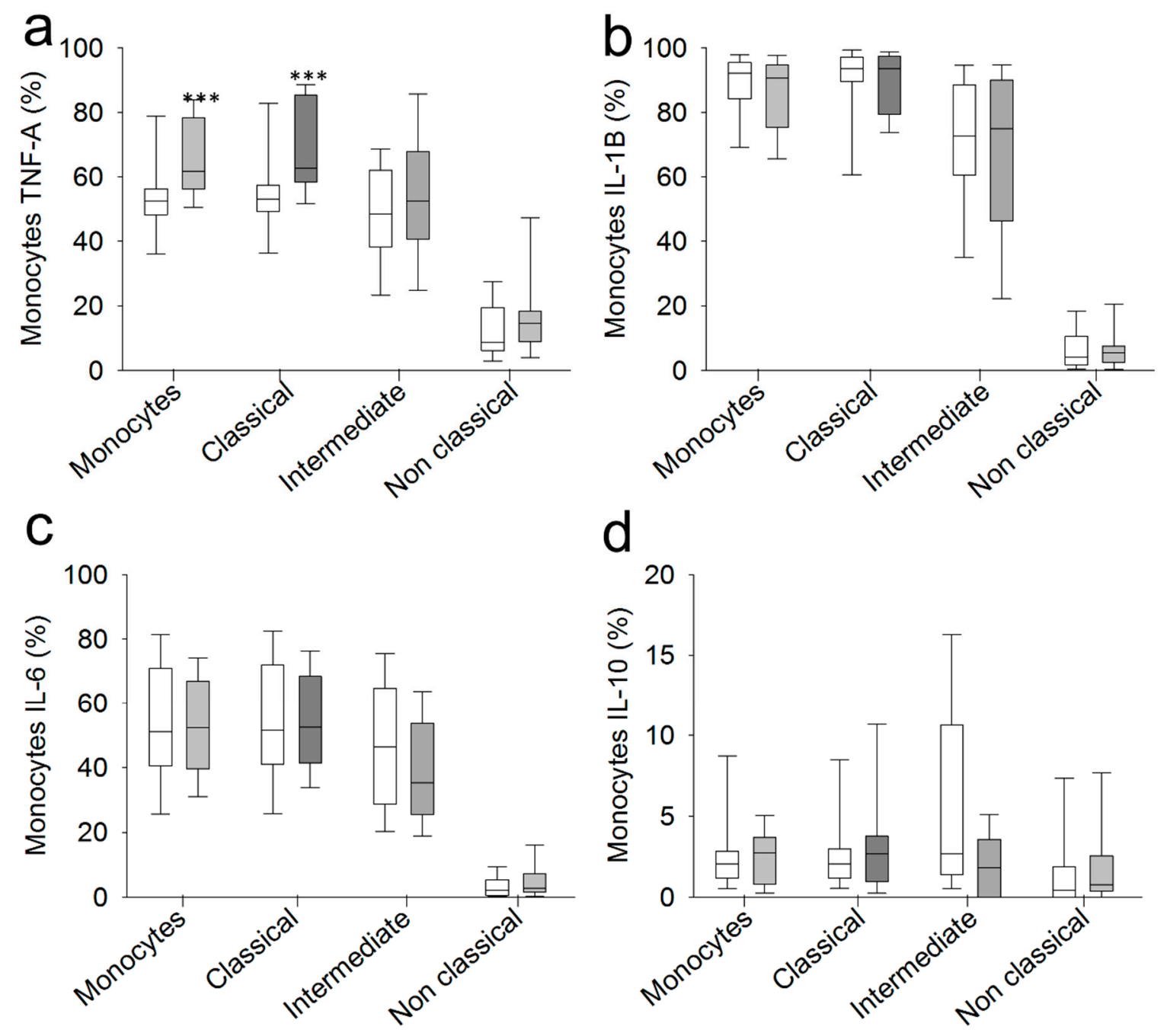

Figure 3. Cytokine production by circulating monocytes from chronic SCI patients. Percentages of monocytes producing TNF- $\alpha$ : (a) IL-1 $\beta$; (b) IL-6; (c) and IL-10 (d) among circulating monocytes and the CD14 ${ }^{\text {+high }}$ CD16 ${ }^{-}, \mathrm{CD}_{14}{ }^{+ \text {high }} \mathrm{CD} 16^{+}$and $\mathrm{CD} 14^{+ \text {low }} \mathrm{CD} 16^{+}$monocyte subsets from chronic SCI patients (gray box) and healthy controls (white box). ${ }^{* * *}$ Significant difference between patients and healthy controls $(p<0.001)$.

Moreover, in chronic SCI patients, we found a significant direct correlation between serum TNF- $\alpha$ levels and LPS-induced TNF- $\alpha$ production in monocytes $(\mathrm{r}=0.43, p<0.05)$

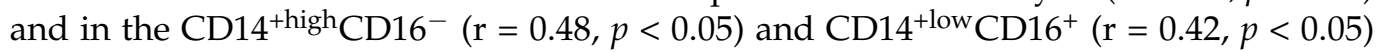
monocyte subsets (Figure 5). We also found a significant negative correlation between serum TNF- $\alpha$ concentrations and TLR4 expression in the monocyte population $(\mathrm{r}=-0.31$, $p<0.05)$ and in the $\mathrm{CD} 14^{\text {thigh }} \mathrm{CD} 16^{-}(\mathrm{r}=-0.31, p<0.05)$ and $\mathrm{CD} 14^{\text {+high }} \mathrm{CD} 16^{+}$monocyte subsets $(r=-0.32, p<0.05)$ but not in $\mathrm{CD}_{1} 4^{-} \mathrm{CD} 16^{+}$monocytes $(\mathrm{r}=-0.2, p<0.24)$. We found no significant correlations between serum TNF- $\alpha$ levels and TLR2 and TLR9 expression in monocytes from the two groups of subjects. In the HC group, there were no significant correlations among serum TNF- $\alpha$ levels, LPS-induced monocyte TNF- $\alpha$ expression, and TLR expression in circulating monocytes (data not shown). 
a

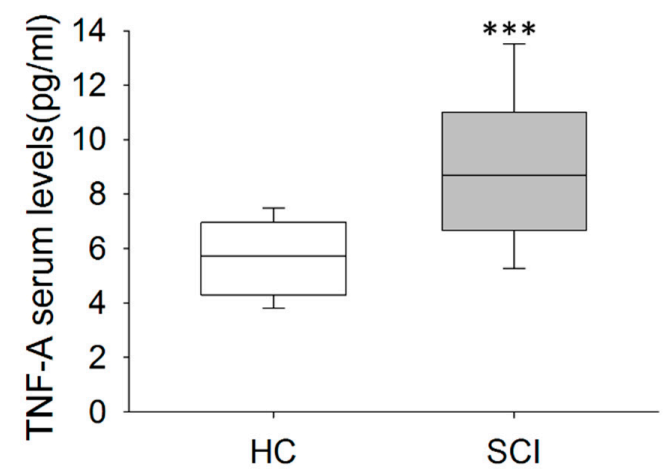

C
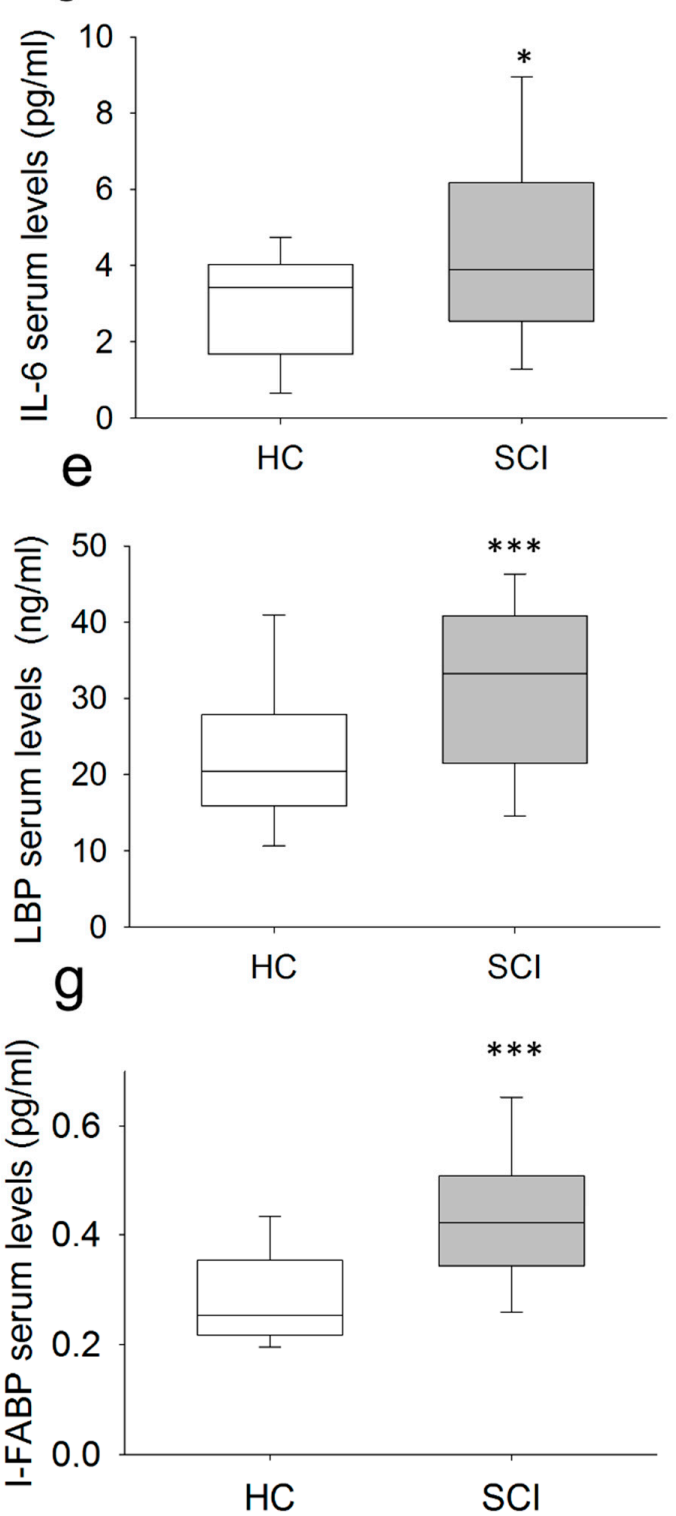

$\mathrm{b}$
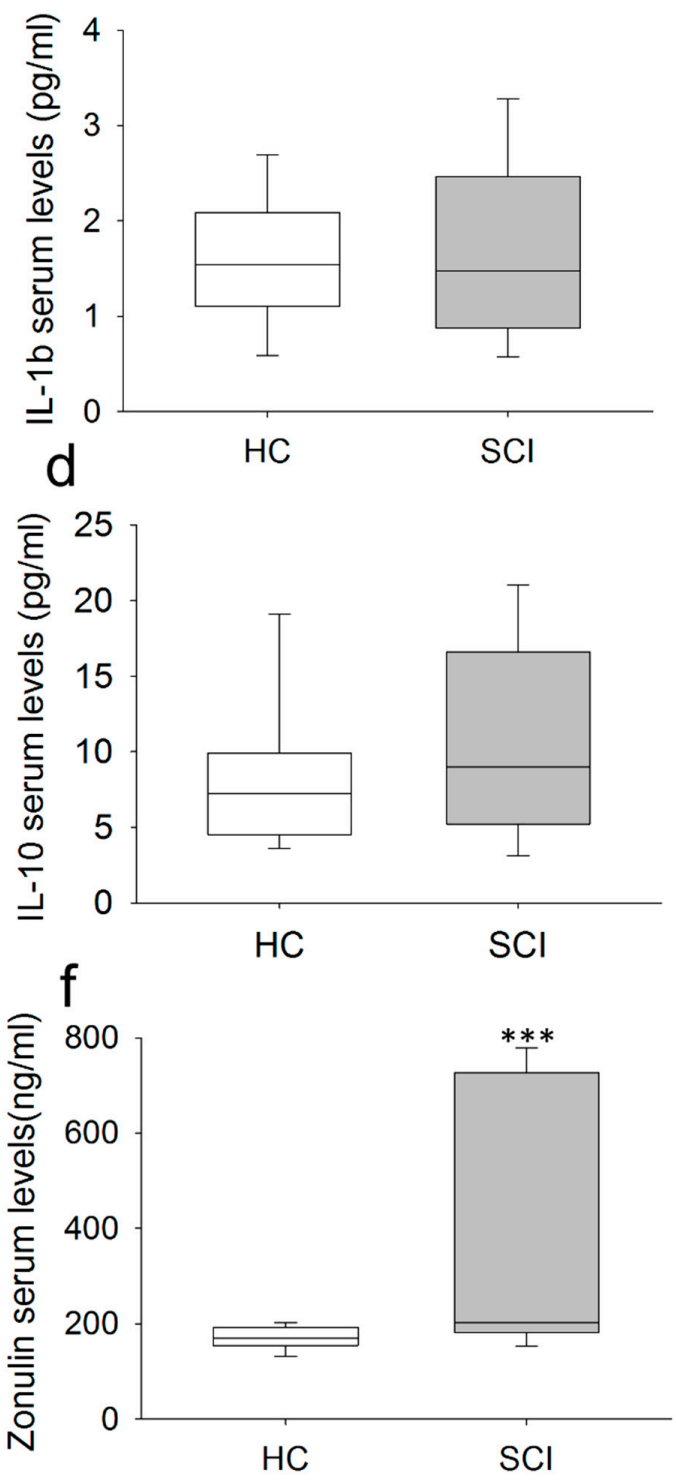

Figure 4. Determination of serum soluble mediators in chronic SCI patients. Serum concentrations of TNF- $\alpha$ : (panel (a)) IL-1ß; (b) IL-6; (c) IL-10; (d) LBP; (e) zonulin; (f) and I-FABP; (g) in chronic SCI patients (gray box) and healthy controls (white box) are shown. * Significant difference between patients and healthy controls $(p<0.05)$. ** Significant difference between patients and healthy controls $(p<0.001)$. 

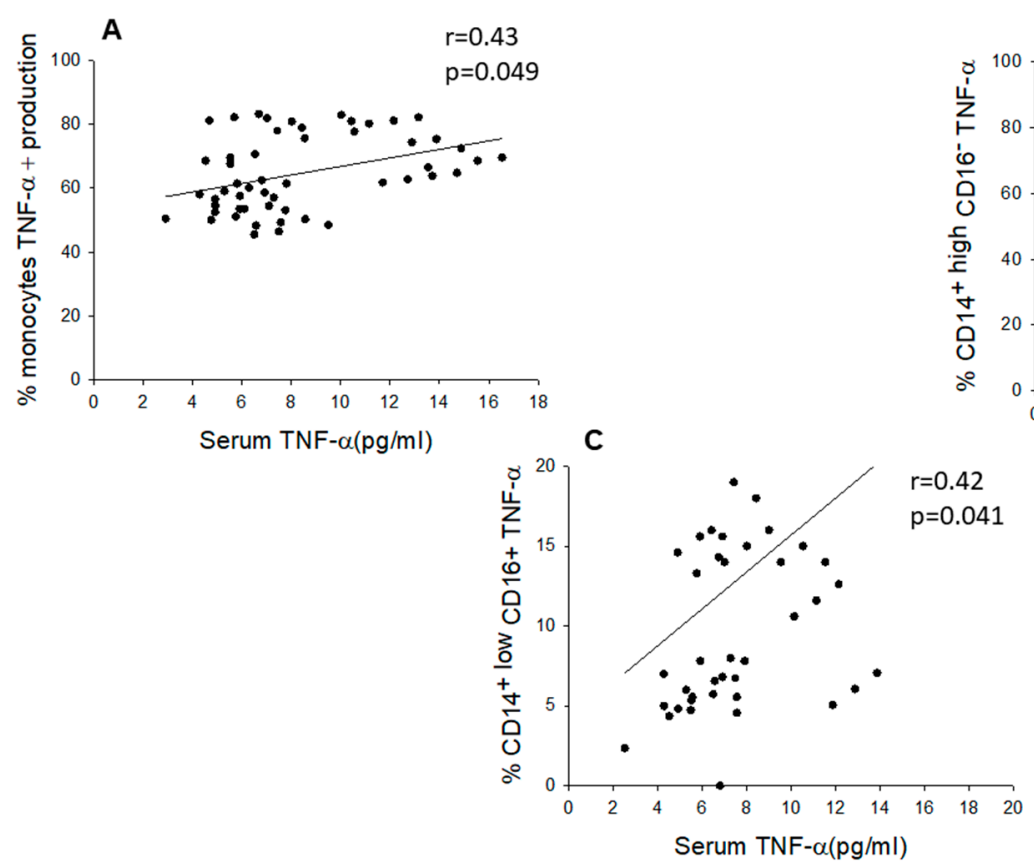

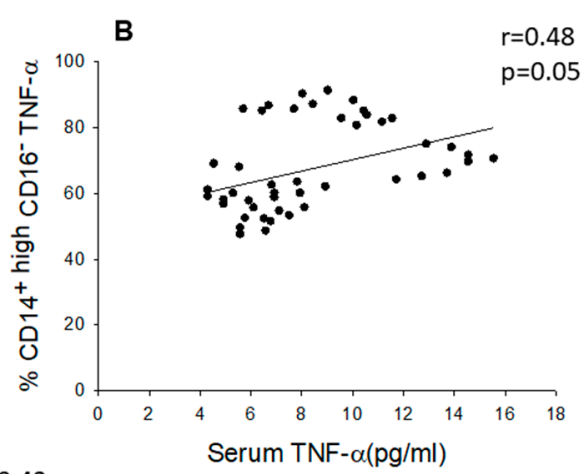

$=0.48$

$p=0.05$

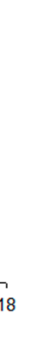


a

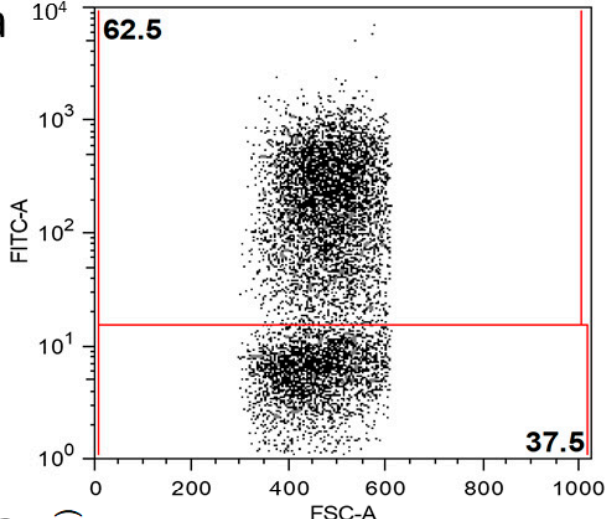

C

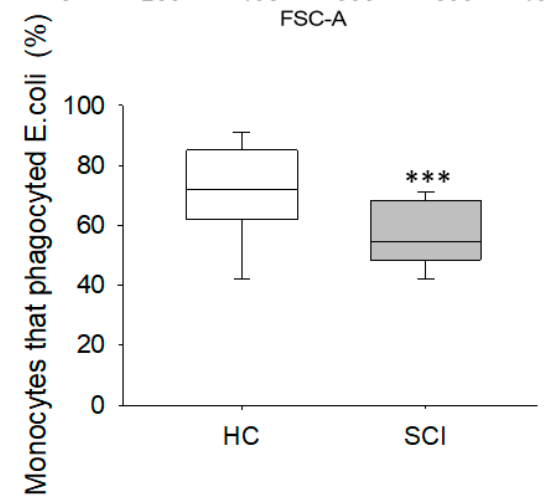

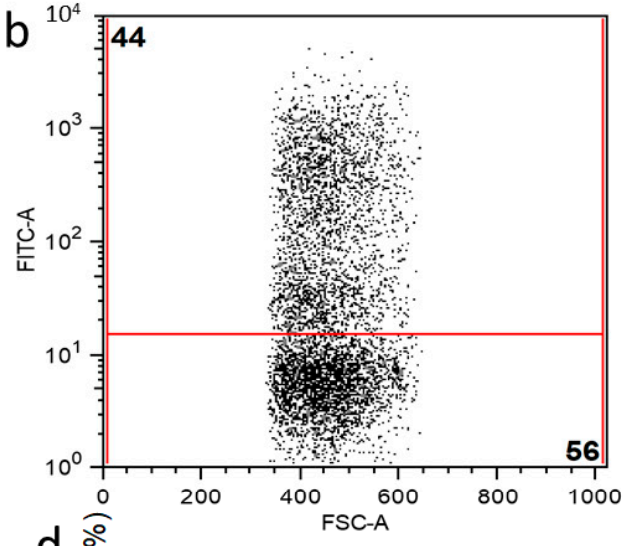

$\mathrm{d} \stackrel{2}{\mathrm{o}}$

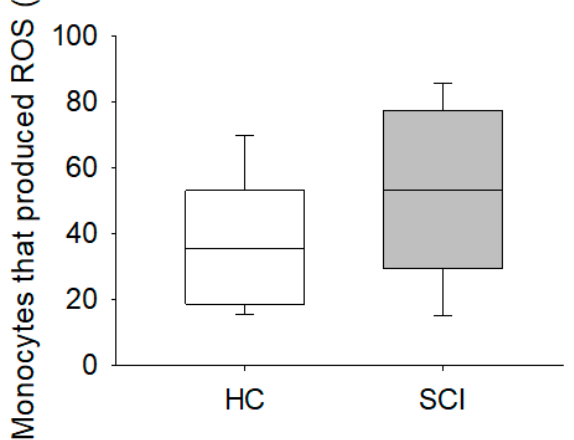

Figure 6. Phagocytosis and ROS production by circulating monocytes from chronic SCI patients. Representative analysis of monocytes that phagocytosed E. coli in a healthy control: (a) and a chronic SCI patient; (b). The percentages of peripheral blood monocytes that phagocytosed E. coli; (c) and that produced ROS; (d) in chronic SCI patients (gray box) and healthy controls (white box) are shown. $* * *$ Significant difference between patients and healthy controls $(p<0.001)$.

\section{Injury level}

a
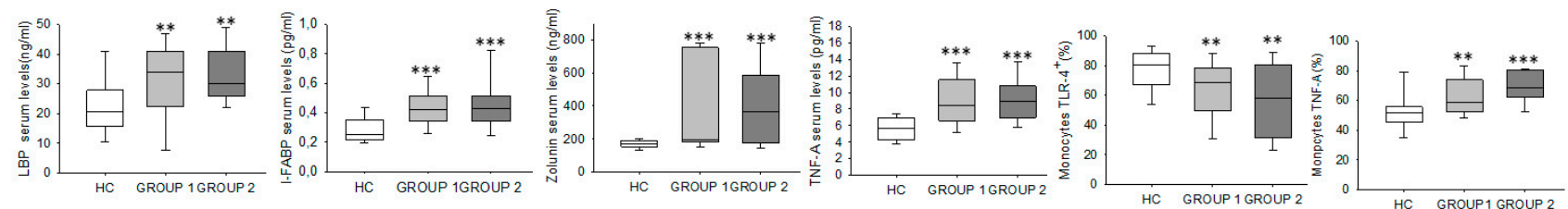

AIS
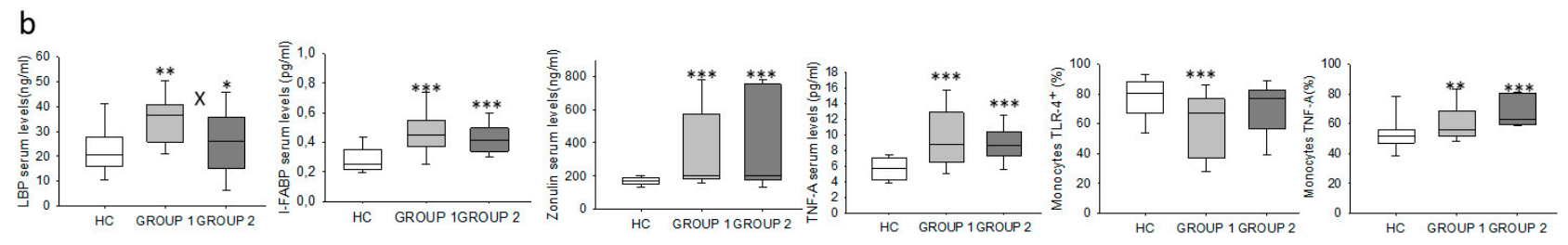

Figure 7. Clinical stratification of chronic SCI patients. Different immune system parameters (LBP, I-FABP, zonulin, serum TNF- $\alpha$, TLR4 and TNF- $\alpha$-producing monocytes) in chronic SCI patients (gray box) and healthy controls (white box) were analyzed. Patients were stratified by the level of the spine lesion: (a), from C1 to T5 (Group 1) versus from T6 to L6 (Group 2), and by the AIS score; (b), as follows: group 1 covers A and B AIS scores, and group 2 covers C, D and E AIS scores. ${ }^{*}$ Significant difference between patients and healthy controls $(p<0.05) .{ }^{* *}$ Significant difference between patients and healthy controls $(p<0.01)$. ${ }^{* *}$ Significant difference between patients and healthy controls $(p<0.001)$. X Significant difference between both groups of patients $(p<0.01)$. 
Finally, we classified chronic SCI patients into two groups according to their AIS scores: group 1, which covered A and B AIS scores, and group 2, which covered C, D and E AIS scores. We found a significant increase in the serum concentration of LBP in group 1 and group 2 compared to the concentration observed in HCs, as well as a significant decrease in group 2 compared to group 1 (Figure $7 \mathrm{~b}$ ). Monocyte TNF- $\alpha$ production as well as serum levels of I-FABP, zonulin and TNF- $\alpha$ were significantly elevated in both groups compared to the levels observed in HCs. We also found a significant decrease in the percentage of monocytes that expressed TLR4 in group 1 compared to the values observed for HCs.

\section{Discussion}

In this paper, we have demonstrated that chronic SCI patients without associated inflammatory and infectious diseases show functional impairment of circulating monocytes, with diminished TLR4 expression, increased LPS-induced TNF- $\alpha$ production and defective phagocytosis. These patients also show a systemic proinflammatory state characterized by enhanced serum TNF- $\alpha$ and IL- 6 levels. Furthermore, augmented circulating levels of LBP, I-FABP, and zonulin are found in chronic SCI patients, indicating increased bacterial translocation and gut barrier damage.

The function of the immune system in patients with chronic SCI remains poorly defined. Contradictory results have been reported for T lymphocyte counts, subset distributions, and functions [21,33-37]. Monocytes are a cornerstone of the immune system that links innate and adaptive immunity and plays critical roles in the response to bacterial infections and in the induction and regulation of the inflammatory response [23]. Our findings show that chronic SCI patients have normal monocyte counts, which is consistent with a previous report [36]. Furthermore, reduced monocyte counts have been reported 4-5 months after SCI in acute patients [37]. Moreover, the distribution of the $\mathrm{CD} 14^{\text {+high }} \mathrm{CD} 16^{-}, \mathrm{CD} 14^{\text {+high }} \mathrm{CD} 16^{+}$, and $\mathrm{CD} 14^{+ \text {low }} \mathrm{CD} 16^{+}$circulating monocyte subsets is also normal in these patients.

Members of the TLR family play critical roles as regulators of innate and adaptive immune responses. Interestingly, the expression of TLR4 on monocytes from chronic SCI patients is diminished, and this observation can be explained by the observed reduction in the $\mathrm{CD}_{14}{ }^{\text {high }} \mathrm{CD} 16^{-}$and $\mathrm{CD} 14^{\text {+high }} \mathrm{CD} 16^{+}$subsets. However, chronic SCI patients show normal TLR2 expression on monocytes and in all three monocyte subsets. Alterations in monocyte TLR4 expression have been described in acute and chronic diseases. TLR4 overexpression on monocytes has been found in different noninfectious diseases, such as atrial fibrillation and major depression [38]. In contrast, sepsis patients show decreased TLR4 expression on monocytes that has been associated with worse outcomes and mortality $[39,40]$. We also found increased TLR9 expression on monocytes from chronic SCI patients, which could be explained by the enhanced expression found on the CD14 ${ }^{\text {high }} \mathrm{CD} 16^{-}$and $\mathrm{CD} 14^{\text {+high }} \mathrm{CD} 16^{+}$monocyte subsets. TLR9, which binds bacterial DNA, is an intracellular molecule that is also found on the cell surface $[10,41,42]$. It has been proposed that the cell surface form of TLR9 binds bacterial DNA and that the ligand is then transferred from the cell surface to the intracellular compartment [42,43]. Increased TLR9 expression has been reported in chronic infectious and noninfectious inflammatory diseases, such as systemic lupus erythematosus, cutaneous leishmaniasis, chronic hepatitis B, and acute sepsis [44-47].

Monocytes can produce a plethora of cytokines that are essential for the adequate regulation of immune responses. In this study, we show a clear enhancement of monocyte TNF$\alpha$ production, but the levels of IL-1, IL- 6 and IL-10 were normal. The increased monocyte TNF- $\alpha$ expression observed in chronic SCI patients is linked to the CD14 ${ }^{\text {high }}$ CD16 ${ }^{-}$subset. It is known that monocytes, of which a majority of cells are in the CD14 ${ }^{\text {high }}$ CD16 ${ }^{-}$subset, secrete cytokines, including TNF- $\alpha$, IL-1, IL- 6 and IL-10, and release inflammatory mediators when stimulated with LPS [48]. In contrast, CD14 ${ }^{\text {high }} \mathrm{CD} 16^{+}$and CD $14^{+ \text {low }} \mathrm{CD} 16^{+}$ monocytes from chronic SCI patients show normal TNF- $\alpha$, IL-1, IL-6 and IL-10 production by monocytes after LPS stimulation. These $\mathrm{CD} 14^{+ \text {low }} \mathrm{CD} 16^{+}$monocytes mainly respond 
to nucleic acid stimulation [49]. Interestingly, decreased secretion of IP-10 by monocytes from chronic SCI patients has been described [36]. Thus, patients with chronic SCI show a specific proinflammatory pattern of altered monocyte cytokine production. This abnormal pattern of monocyte subset distribution has not been previously described in inflammatory diseases $[48,50,51]$. Furthermore, we found a marked defect in E. coli uptake but normal ROS generation in monocytes from patients with chronic SCI. These results indicate an impaired phagocytic ability but preserved monocyte intracellular microbicidal activity in these patients. Interestingly, monocyte ROS generation is preserved or even enhanced in septic patients, suggesting that oxidative metabolism and cytokine production are differentially regulated in monocytes from septic patients [52].

Increased serum levels of TNF- $\alpha$ and IL- 6 have been associated with inflammatory diseases $[53,54]$. Consistent with previous studies, we found an increase in the inflammatory mediators TNF- $\alpha$ and IL- 6 but normal IL- $1 \beta$ and IL-10 levels in chronic SCI patients $[20,55]$. Interestingly, serum TNF- $\alpha$ levels correlate with the production of this cytokine by LPSstimulated monocytes from chronic SCI patients. The source of the increased IL-6 levels cannot be ascribed to monocytes since the production of this cytokine was normal. Several immune and nonimmune cells may produce IL-6, and its production can be induced by TNF- $\alpha[56]$.

Several mechanisms may be involved in the pathogenesis of the proinflammatory monocyte abnormalities found in chronic SCI patients, and our findings help to improve our understanding of this immune system alteration. To the best of our knowledge, this is the first report of elevated circulating LBP levels in chronic SCI patients. The hepatic synthesis of LBP is promoted by LPS, and LPS-LBP complexes bind to CD14 on the monocyte surface. LBP peaks in the plasma 2 to 3 days after transient bacteriemia or endotoxemia, and the levels remain increased up to $72 \mathrm{~h}$ later [30]. Indeed, in several clinical settings, plasma LBP seems to better reflect long-term exposure to bacteria and their endotoxins than endotoxin itself $[32,57]$. Increased serum LPS levels have been associated with higher circulating levels of TNF- $\alpha$ and IL- 6 and increased TNF- $\alpha$ expression on monocytes [58]. Furthermore, increased LBP production has been associated with decreased expression of TLR4 on host immune cells [39]. Thus, the clinical setting described here differs from that of sepsis and septic patients, in which massive, acute LPS exposure promotes very high LBP concentrations that inhibit the LPS response by human monocytes and is therefore thought to be protective [59].

It was recently reported that experimental SCI is associated with increased intestinal permeability and bacterial translocation from the gut [60]. We investigated gut barrier damage in chronic SCI patients by quantifying I-FABP and zonulin, which are validated markers [61,62]. The increased serum I-FABP and zonulin levels observed in chronic SCI patients might reflect a loss of the integrity of the intestinal barrier. Increased intestinal permeability favors bacterial translocation [63]. Therefore, increased intestinal permeability in SCI patients may play a role in the observed increase in LBP levels. The urinary tract does not appear to be a relevant source of bacterial translocation in our chronic SCI patients since they had neither clinical manifestations of UTI nor positive urine cultures. Furthermore, the increased LBP levels cannot be explained by a clinical infection because the presence of recent acute or chronic infections was a patient exclusion criterion in our study.

In animal models, the immune disturbance found in acute SCI has been related to the involvement of the sympathetic autonomous nervous system and neuroimmune regulation [64]. However, in humans, the relevance of this impairment has not been established. Contradictory reports about the relationship between the level of injury and the impairment of NK cells have been made [6,33-35]. Our results show that gut barrier damage, bacterial translocation, monocyte disturbance, and systemic proinflammatory conditions in chronic SCI patients are independent of the thoracic level of the lesion.

The monocyte dysfunction and systemic proinflammatory cytokine pattern that are associated with increased bacterial translocation in chronic SCI patients provide clues to improve our understanding of the clinical complications that develop in these patients. Im- 
paired monocyte phagocytic activity and defective TLR4 expression in the CD14 ${ }^{\text {thigh }} \mathrm{CD} 16^{-}$ and $\mathrm{CD} 14^{\text {+high }} \mathrm{CD} 16^{+}$monocyte subsets might be involved in common causes, predominantly septicemia, of death in the years following SCI $[65,66]$. Indeed, TLR4 plays a critical role in the clinical response to intraperitoneal $E$. coli, and TLR4 modulates the phagocytosis of bacteria by peritoneal macrophages [67]. Furthermore, increased bacterial translocation defined by enhanced LPS levels has also been associated with an increased prevalence of infections and mortality in different clinical settings, including those with augmented gut barrier damage and monocyte dysfunction $[28,58]$.

Our findings demonstrate that patients with chronic SCI suffer an unexpected systemic inflammatory state, with severe disturbances of monocyte function and pathogenic compromise of the intestinal barrier, as summarized in Figure 8. Chronic SCI patients show a critical compromise of the intestinal barrier, as shown by the enhanced plasma levels of IFABP and zonulin. This impairment favors a subsequent increase in bacterial translocation, as demonstrated by the augmented LBP levels found in chronic SCI patients. This bacterial pressure appears to be involved in maintaining monocyte overstimulation. Furthermore, monocytes from chronic SCI patients display defective phagocytic activity. These findings demonstrate that chronic SCI patients suffer not only a motor, sensory and/or autonomous nervous system disease but also a systemic inflammatory disease. These patients have severe comorbidities, such as premature coronary heart disease, metabolic syndrome and diabetes mellitus $[10,68]$. Activated monocytes and proinflammatory cytokines are clearly involved in the pathogenesis of accelerated atherogenesis and insulin resistance in different chronic inflammatory diseases $[69,70]$. Thus, the immune disturbances found in chronic SCI patients may also favor the appearance of these high-morbidity diseases. Taken together, our findings suggest that we should consider noncomplicated chronic SCI as a systemic inflammatory disease with monocyte dysfunction and increased bacterial translocation across the intestinal barrier.

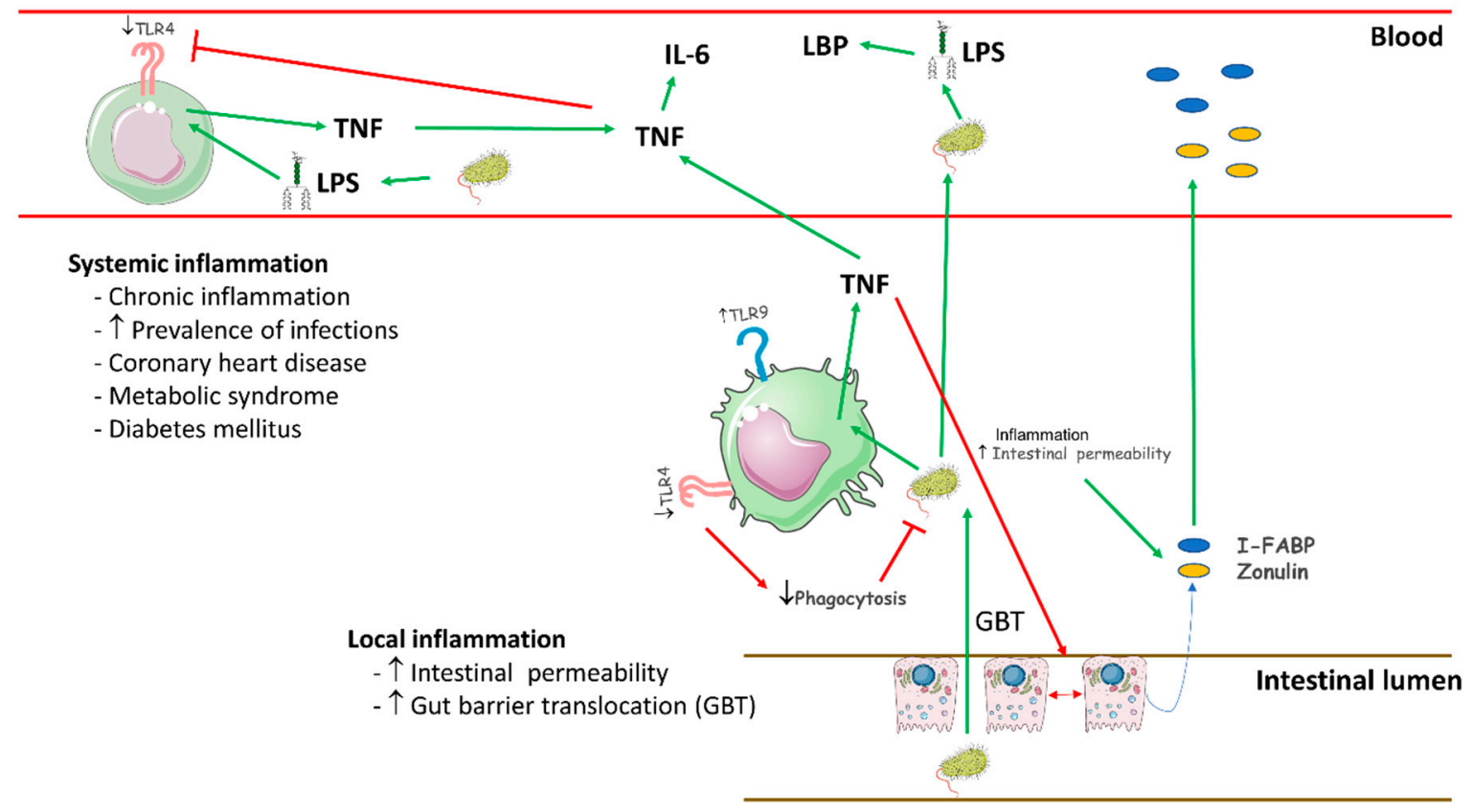

Figure 8. Schematic representation of pathology in chronic SCI patients.

One limitation to this study might be the limited number of participants. In addition, we have not carried out a longitudinal study of the patients. Moreover, the immune system is a complex system that involves many populations and molecules that must be analyzed together. Therefore, it would be interesting to analyze other compartments of the immune system as well as their functional interaction between them 
Our findings provide an innovative understanding of chronic SCI that will support the development of new strategies for preventing the severe comorbidities that these patients suffer. Future translational and longitudinal clinical studies must define the potential biomarker value of immune system and/or bacteria-dependent host parameters for the development of infectious and noninfectious complications. Furthermore, these results support the need to investigate new immunomodulatory and microbiological strategies in patients with chronic SCI. These immune disturbances and the associated bacterial translocation must be analyzed in the whole population of patients, including those with inflammatory or septic complications.

\section{Materials and Methods}

\subsection{Study Protocol}

In this prospective study, we included 56 chronic SCI patients using the following inclusion criteria: (1) $\geq 18$ years of age; (2) a history of SCI, with at least 1 year of SCI at any level; (3) SCI with any severity, including grades A to E classified with the American Spinal Injury Association (ASIA) Impairment Scale (AIS). A physiatrist board-certified in SCI medicine evaluated the subjects' injuries according to the International Standards for Neurologic Classification of Spinal Cord Injury [71,72]. Potential subjects were excluded if they had (1) a concurrent infection complication, such as a urinary tract infection (UTI) or a respiratory infection with positive urine culture in the last three months; (2) chronic bacterial or viral infection; (3) pressure ulcers in the last 12 months; (4) received steroids or immunomodulatory drugs in the last three months; (5) an autoimmune disease; (6) a severe cardiovascular disease; (7) a hematopoietic, lung, hepatic or renal disorder; (8) an endocrine or metabolic disease, including diabetes mellitus; (9) a history of malignancy; (10) immunodeficiency and malnutrition; (11) pregnancy or lactation; and (12) psychiatric disorders. The patients were studied in parallel with 28 sex- and age-matched HCs.

The experimental protocol included a detailed clinical assessment that encompassed several clinical parameters-some of them directly related to the SCI but others needed for the correct interpretation of immunological data-and a blood sample for the determination of routine hematological and biochemical parameters along with the immunological parameters detailed below. Clinical data from the SCI subjects were obtained during a routine medical examination in an outpatient clinic in the Physical Medicine and Rehabilitation Department, and included: (1) baseline demographic characteristics; (2) time from and mechanism of initial injury; (3) neurologic injury level and severity; (4) tonic and phasic spasticity; (5) presence, type and severity of pain; (6) medical history of infections and other symptoms evocative of some chronic SCI complication; (7) comorbid conditions; (8) concurrent medications; (9) fatigue; (10) depression and anxiety levels; (11) level of independence in daily living activities; (12) and a measure of one's own quality of life and health status perception.

This study was approved by the institutional and regional clinical ethics committee. Written informed consent was obtained from all subjects before study enrollment.

Clinical data from the SCI patients were obtained during a routine medical examination at an outpatient clinic in the Physical Medicine and Rehabilitation Department and included the following. This study was approved by the institutional and regional clinical ethics committee. Written informed consent was obtained from all subjects before study enrollment.

Blood samples were drawn from all subjects via standard venipuncture using established aseptic technique. Samples were obtained from the chronic SCI patients at the time of the clinical evaluation in the outpatient clinic area. Serum samples from 56 subjects with chronic SCI and 28 uninjured subjects were included for analysis. After collection, the samples were centrifuged, and the serum was isolated, aliquoted, and stored at $-80{ }^{\circ} \mathrm{C}$ until analysis. 


\subsection{Isolation of Peripheral Blood Mononuclear Cells}

Peripheral blood mononuclear cells (PBMCs) were separated by Ficoll-Hypaque (Lymphoprep ${ }^{\mathrm{TM}}$, Axis-Shield, Oslo, Norway) gradient centrifugation. The cells were then resuspended in RPMI 1640 (BioWhittaker Products, Verviers, Belgium) supplemented with 10\% heat-inactivated fetal calf serum, $25 \mathrm{mM}$ HEPES (BioWhittaker Products) and $1 \%$ penicillin-streptomycin (BioWhittaker Products). Cell enumeration was performed by conventional light microscopy using a Neubauer chamber following the criteria for trypan blue dead cell exclusion.

\subsection{Immunophenotype Studies}

The proportions of monocyte subsets were determined in fresh PBMCs by ten-color polychromatic flow cytometry in a FACSAria cytometer using FACSDiva software (Becton Dickinson, NJ, USA). One million PBMCs were incubated with a combination of the following monoclonal antibodies (MoAbs): CX3CR1-FITC, Slan-PE, HLA-DR-PerCP, CCR2PerCP-Cy5.5, CD11c-PE-CY7, CD3/CD56/CD19-APC, CD62L-APC-A780, CD16-PB, AquaQD565, and CD14-QD655. For these procedures, CD14-QD655, CD16-Alexa405, HLA-DRPerCP, CD3-APC, CD19-APC, CD56-APC, CCR2-PerCP-Cy5.5, and CD62L-Alexa780 were obtained from Becton Dickinson, CX3CR1-FITC and CD11C-PE-CY7 were obtained from e-Biosciences (e-Biosciences, San Diego, CA, USA), SLAN-PE was obtained from Miltenyi (Miltenyi, Bergisch Gladbach, Germany) and Aqua-QD565 was obtained from Invitrogen (Invitrogen, Carlsbad, CA, USA).

The expression of TLRs on monocyte subsets was determined in fresh PBMCs by fivecolor polychromatic flow cytometry in a FACSAria cytometer using FACSDiva software (Becton Dickinson). Fresh PBMCs were labeled with CD14-QD655, CD16-Alexa405, TLR2FITC, TLR4-APC and TLR9-PE (Becton Dickinson) MoAbs.

For all samples, once the MoAbs were added, the cells were incubated for $20 \mathrm{~min}$ at $4{ }^{\circ} \mathrm{C}$ in the dark. After that time, the cells were washed in phosphate-buffered saline (PBS) to eliminate excess antibody, and $100 \mu \mathrm{L}$ of PBS was added for subsequent acquisition by flow cytometry. Analyses were carried out using FlowJo software (TreeStar Inc., Ashland, OR, USA).

\subsection{Intracellular Cytokines}

To analyze the production of cytokines by PBMCs, fresh PBMCs were cultured in ultralow attachment plates (Corning Incorporated, Baltimore, MD, USA) $\left(1 \mathrm{~mL}\right.$ of cells at $10^{6}$ cells $/ \mathrm{mL}$ ) and incubated for $4 \mathrm{~h}$ at $37{ }^{\circ} \mathrm{C}$ with $5 \% \mathrm{CO}_{2}$. PBMC stimulation was performed by adding LPS ( $5 \mu \mathrm{g} / \mathrm{mL}$, Sigma-Aldrich Chemistry, Madrid, Spain) and monensin (50 $\mu \mathrm{g} / \mathrm{mL}$, Sigma). Next, the cells were labeled with CD14-PerCP and CD16-Alexa647 (Becton Dickinson) MoAbs and the vital dye Aqua-QD565. For intracytoplasmic staining, the cells were fixed and permeabilized (Fix and Perm, Caltag Laboratories, Burlingame, CA, USA), and cytokines were stained with IL-1 $\beta$-FITC, IL-10-PE, IL-6-V505, and TNF- $\alpha$-Alexa700 (Becton Dickinson) MoAbs.

\subsection{Flow Cytometry Studies of Oxidation and Phagocytic Activity}

The phagocytic function of circulating monocytes was determined by the intake of Escherichia coli (Phagotest; Becton Dickinson) and the quantification of the oxidative burst activity of monocytes in heparinized human whole blood was determined by the PHAGOBURST test (Becton Dickinson).

\subsection{Quantification of Serum Cytokines Using Luminex}

To study the concentrations of cytokines in the serum, the Milliplex MAP Kit (MERCK, Darmstadt, Germany) was employed using the protocol recommended by MERCK. The plate was read in a Luminex MAGPIX with xPONENT software (Luminex Corporation, Northbrook, IL, USA). 


\subsection{Study of Damage to the Intestinal Barrier}

To study intestinal barrier damage, an analysis of I-FABP and zonulin concentrations in the serum was performed by ELISA. I-FABP was purchased from Hycult Biotech (Hycult Biotech, Wayne, PA, USA), and zonulin was purchased from R\&D Systems (R\&D Systems, Minneapolis, MN, USA). The plate was read in an iMark Microplate Reader at $450 \mathrm{~nm}$ with Microplate Manager Software (Thermo Fisher Scientific, Frederick, MD, USA).

\subsection{Study of the Acute Phase Response}

To study the acute phase response, we determined the concentration of LBP in the serum by ELISA (Abnova, Taipei, Taiwan). The plate was read in an iMark Microplate Reader at $450 \mathrm{~nm}$ with Microplate Manager Software (Thermo Fisher Scientific).

\subsection{Statistical Analysis}

Comparisons between patients and HCs were performed using the nonparametric Mann-Whitney U test. Associations between variables were assessed with the Spearman's rank correlation coefficient by simple linear regression analyses. All calculations were performed using the Statistical Package for the Social Sciences (SPSS, version 22.0, Chicago, IL, USA). Significance was set at $p<0.05$.

Author Contributions: M.A.-M., E.L.-D., A.A., and D.D. were responsible for the study conception and design; S.H. and J.M. were responsible for acquisition of data; S.H., J.M. and D.D. were responsible for analysis and interpretation of data; D.D., E.L.-D., and M.A.-M. drafted the manuscript; D.D., A.A., C.M.-A., D.B., and M.A.-M. critically revised the manuscript for important intellectual content. All authors have read and agreed to the published version of the manuscript.

Funding: This work was partially funded by grants from the Fondo de Investigación de la Seguridad Social (Spain) (FIS PI-14/01935), the Spanish Ministerio de Ciencia y Tecnología, Instituto de Salud Carlos III (PI051871, CIBERehd), the Spanish Ministerio de Economía y Competitividad (SAF201786343-R) and Comunidad de Madrid (B2017/BMD-3804).

Institutional Review Board Statement: The study was conducted according to the guidelines of the Declaration of Helsinki, and approved by the Institutional Review of National Hospital for Paraplegic Patients (10 September 2015).

Informed Consent Statement: Written informed consent was obtained from all subjects before study enrollment.

Conflicts of Interest: The authors declare that they have no competing interests.

Ethical Approval: All procedures performed in studies involving human participants were in accordance with the ethical standards of the institutional and/or national research committee and with the 1964 Helsinki declaration and its later amendments or comparable ethical standards.

\section{References}

1. DeVivo, M.J. Epidemiology of traumatic spinal cord injury: Trends and future implications. Spinal Cord 2012, 50, 365-372. [CrossRef] [PubMed]

2. Bowes, A.L.; Yip, P.K. Modulating inflammatory cell responses to spinal cord injury: All in good time. J. Neurotrauma 2014, 31, 1753-1766. [CrossRef] [PubMed]

3. Donnelly, D.J.; Popovich, P.G. Inflammation and its role in neuroprotection, axonal regeneration and functional recovery after spinal cord injury. Exp. Neurol. 2008, 209, 378-388. [CrossRef] [PubMed]

4. Gadani, S.P.; Walsh, J.T.; Smirnov, I.; Zheng, J.; Kipnis, J. The glia-derived alarmin IL-33 orchestrates the immune response and promotes recovery following CNS injury. Neuron 2015, 85, 703-709. [CrossRef] [PubMed]

5. Jones, T.B. Lymphocytes and autoimmunity after spinal cord injury. Exp. Neurol. 2014, 258, 78-90. [CrossRef]

6. Laginha, I.; Kopp, M.A.; Druschel, C.; Schaser, K.D.; Brommer, B.; Hellmann, R.C.; Watzlawick, R.; Ossami-Saidi, R.R.; Prüss, H.; Failli, V.; et al. Natural killer (NK) cell functionality after human spinal cord injury (SCI): Protocol of a prospective, longitudinal study. BMC Neurol. 2016, 16, 170. [CrossRef]

7. Pajoohesh-Ganji, A.; Knoblach, S.M.; Faden, A.I.; Byrnes, K.R. Characterization of inflammatory gene expression and galectin-3 function after spinal cord injury in mice. Brain Res. 2012, 1475, 96-105. [CrossRef]

8. DiMarco, A.F.; Dawson, N.V. Risk factors for mortality in spinal cord injury. J. Spinal Cord Med. 2014, 37, 670-671. [CrossRef] 
9. Strauss, D.J.; DeVivo, M.J.; Paculdo, D.R.; Shavelle, R.M. Trends in life expectancy after spinal cord injury. Arch. Phys. Med. Rehabil. 2006, 87, 1079-1085. [CrossRef]

10. Khan, B.; Bauman, W.A.; Sinha, A.K.; Kahn, N.N. Non-conventional hemostatic risk factors for coronary heart disease in individuals with spinal cord injury. Spinal Cord 2011, 49, 858-866. [CrossRef]

11. Lavela, S.L.; Weaver, F.M.; Goldstein, B.; Chen, K.; Miskevics, S.; Rajan, S.; Gater, D.R., Jr. Diabetes mellitus in individuals with spinal cord injury or disorder. J. Spinal Cord Med. 2006, 29, 387-395. [CrossRef] [PubMed]

12. Kopp, M.A.; Druschel, C.; Meisel, C.; Liebscher, T.; Prilipp, E.; Watzlawick, R.; Cinelli, P.; Niedeggen, A.; Schaser, K.D.; Wanner, G.A.; et al. The SCIentinel study-prospective multicenter study to define the spinal cord injury-induced immune depression syndrome (SCI-IDS)-study protocol and interim feasibility data. BMC Neurol. 2013, 13, 168. [CrossRef] [PubMed]

13. Schwab, J.M.; Zhang, Y.; Kopp, M.A.; Brommer, B.; Popovich, P.G. The paradox of chronic neuroinflammation, systemic immune suppression, autoimmunity after traumatic chronic spinal cord injury. Exp. Neurol. 2014, 258, 121-129. [CrossRef] [PubMed]

14. Gadani, S.P.; Walsh, J.T.; Lukens, J.R.; Kipnis, J. Dealing with danger in the CNS: The response of the immune system to injury. Neuron 2015, 87, 47-62. [CrossRef]

15. Chaudhry, R.; Madden-Fuentes, R.J.; Ortiz, T.K.; Balsara, Z.; Tang, Y.; Nseyo, U.; Wiener, J.S.; Ross, S.S.; Seed, P.C. Inflammatory response to Escherichia coli urinary tract infection in the neurogenic bladder of the spinal cord injured host. J. Urol. 2014, 191, 1454-1461. [CrossRef]

16. Schedlowski, M.; Engler, H.; Grigoleit, J.S. Endotoxin-induced experimental systemic inflammation in humans: A model to disentangle immune-to-brain communication. Brain Behav. Immun. 2014, 35, 1-8. [CrossRef]

17. Kwon, B.K.; Stammers, A.M.T.; Belanger, L.M.; Bernardo, A.; Chan, D.; Bishop, C.M.; Slobogean, G.P.; Zhang, H.; Umedaly, H.; Giffin, M.; et al. Cerebrospinal fluid inflammatory cytokines and biomarkers of injury severity in acute human spinal cord injury. J. Neurotrauma 2010, 27, 669-682. [CrossRef]

18. Hausmann, O.N. Post-traumatic inflammation following spinal cord injury. Spinal Cord 2003, 41, 369-378. [CrossRef]

19. Iversen, P.O.; Hjeltnes, N.; Holm, B.; Flatebø, T.; Strøm-Gundersen, I.; Rønning, W.; Stanghelle, J.; Benestad, H.B. Depressed immunity and impaired proliferation of hematopoietic progenitor cells in patients with complete spinal cord injury. Blood 2000, 96, 2081-2083. [CrossRef]

20. Stein, A.; Panjwani, A.; Sison, C.; Rosen, L.; Chugh, R.; Metz, C.; Bank, M.; Bloom, O. Pilot study: Elevated circulating levels of the proinflammatory cytokine macrophage migration inhibitory factor in patients with chronic spinal cord injury. Arch. Phys. Med. Rehabil. 2013, 94, 1498-1507. [CrossRef]

21. Monahan, R.; Stein, A.; Gibbs, K.; Bank, M.; Bloom, O. Circulating T cell subsets are altered in individuals with chronic spinal cord injury. Immunol. Res. 2015, 63, 3-10. [CrossRef] [PubMed]

22. Fleming, J.C.; Norenberg, M.D.; Ramsay, D.A.; Dekaban, G.A.; Marcillo, A.E.; Saenz, A.D.; Pasquale-Styles, M.; Dietrich, W.D.; Weaver, L.C. The cellular inflammatory response in human spinal cords after injury. Brain 2006, 129, 3249-3269. [CrossRef] [PubMed]

23. Auffray, C.; Sieweke, M.H.; Geissmann, F. Blood monocytes: Development, heterogeneity, and relationship with dendritic cells. Annu. Rev. Immunol. 2009, 27, 669-692. [CrossRef] [PubMed]

24. Ziegler-Heitbrock, L.; Ancuta, P.; Crowe, S.; Dalod, M.; Grau, V.; Hart, D.N.; Leenen, P.J.M.; Liu, Y.J.; MacPherson, G.; Randolph, G.J.; et al. Nomenclature of monocytes and dendritic cells in blood. Blood 2010, 116, e74-e80. [CrossRef]

25. Takeuchi, O.; Akira, S. Pattern recognition receptors and inflammation. Cell 2010, 140, 805-820. [CrossRef]

26. Murray, P.J. Immune regulation by monocytes. Semin. Immunol. 2018, 35, 12-18. [CrossRef]

27. Hirayama, D.; Iida, T.; Nakase, H. The phagocytic function of macrophage-enforcing innate immunity and tissue homeostasis. Int. J. Mol. Sci. 2017, 19, 92. [CrossRef]

28. Shapouri-Moghaddam, A.; Mohammadian, S.; Vazini, H.; Taghadosi, M.; Esmaeili, S.A.; Mardani, F.; Seifi, B.; Mohammadi, A.; Afshari, J.T.; Sahebkar, A. Macrophage plasticity, polarization, and function in health and disease. J. Cell. Physiol. 2018, 233, 6425-6440. [CrossRef]

29. Kigerl, K.A.; Mostacada, K.; Popovich, P.G. Gut microbiota are disease-modifying factors after traumatic spinal cord injury. Neurotherapeutics 2018, 15, 60-67. [CrossRef]

30. Schumann, R.R.; Latz, E. Lipopolysaccharide-binding protein. Chem. Immunol. 2000, 74, 42-60.

31. Albillos, A.; de-la-Hera, A.; Alvarez-Mon, M. Serum lipopolysaccharide-binding protein prediction of severe bacterial infection in cirrhotic patients with ascites. Lancet 2004, 363, 1608-1610. [CrossRef]

32. Tudesq, J.J.; Dunyach-Remy, C.; Combescure, C.; Doncesco, R.; Laureillard, D.; Lavigne, J.P.; Sotto, A. Microbial translocation is correlated with HIV evolution in HIV-HCV co-infected patients. PLoS ONE 2017, 12, e0183372. [CrossRef] [PubMed]

33. Campagnolo, D.I.; Bartlett, J.A.; Keller, S.E. Influence of neurological level on immune function following spinal cord injury: A review. J. Spinal Cord Med. 2000, 23, 121-128. [CrossRef] [PubMed]

34. Campagnolo, D.I.; Dixon, D.; Schwartz, J.; Bartlett, J.A.; Keller, S.E. Altered innate immunity following spinal cord injury. Spinal Cord 2008, 46, 477-481. [CrossRef]

35. Campagnolo, D.I.; Keller, S.E.; DeLisa, J.A.; Glick, T.J.; Sipski, M.L.; Schleifer, S.J. Alteration of immune system function in tetraplegics. Am. J. Phys. Med. Rehabil. 1994, 73, 387-393. [CrossRef] 
36. Gucluler, G.; Adiguzel, E.; Gungor, B.; Kahraman, T.; Gursel, M.; Yilmaz, B.; Gursel, I. Impaired toll like receptor-7 and 9 induced immune activation in chronic spinal cord injured patients contributes to immune dysfunction. PLOS ONE 2017, 12, e0171003. [CrossRef]

37. Riegger, T.; Conrad, S.; Liu, K.; Schluesener, H.J.; Adibzahdeh, M.; Schwab, J.M. Spinal cord injury-induced immune depression syndrome (SCI-IDS). Eur. J. Neurosci. 2007, 25, 1743-1747. [CrossRef]

38. Gurses, K.M.; Kocyigit, D.; Yalcin, M.U.; Canpinar, H.; Yorgun, H.; Sahiner, M.L.; Kaya, E.B.; Oto, M.A.; Ozer, N.; Guc, D.; et al. Monocyte toll-like receptor expression in patients with atrial fibrillation. Am. J. Cardiol. 2016, 117, 1463-1467. [CrossRef]

39. Salomão, R.; Martins, P.S.; Brunialti, M.K.C.; da Luz Fernandes, M.; Martos, L.S.W.; Mendes, M.E.; Gomes, N.E.; Rigato, O. TLR signaling pathway in patients with sepsis. Shock 2008, 30, 73-77. [CrossRef]

40. Wiersinga, W.J.; van't Veer, C.; van den Pangaart, P.S.; Dondorp, A.M.; Day, N.P.; Peacock, S.J.; van der Poll, T. Immunosuppression associated with interleukin-1R-associated-kinase-M upregulation predicts mortality in Gram-negative sepsis (melioidosis). Crit. Care Med. 2009, 37, 569-576. [CrossRef]

41. Eaton-Bassiri, A.; Dillon, S.B.; Cunningham, M.; Rycyzyn, M.A.; Mills, J.; Sarisky, R.T.; Mbow, M.L. Toll-like receptor 9 can be expressed at the cell surface of distinct populations of tonsils and human peripheral blood mononuclear cells. Infect. Immun. 2004, 72, 7202-7211. [CrossRef] [PubMed]

42. Taylor, P.R.; Tsoni, S.V.; Willment, J.A.; Dennehy, K.M.; Rosas, M.; Findon, H.; Haynes, K.; Steele, C.; Botto, M.; Gordon, S.; et al. Dectin-1 is required for beta-glucan recognition and control of fungal infection. Nat. Immunol. 2007, 8, 31-38. [CrossRef]

43. Ewald, S.E.; Lee, B.L.; Lau, L.; Wickliffe, K.E.; Shi, G.P.; Chapman, H.A.; Barton, G.M. The ectodomain of Toll-like receptor 9 is cleaved to generate a functional receptor. Nature 2008, 456, 658-662. [CrossRef]

44. Baiyee, E.E.; Flohe, S.; Lendemans, S.; Bauer, S.; Mueller, N.; Kreuzfelder, E.; Grosse-Wilde, H. Expression and function of Toll-like receptor 9 in severely injured patients prone to sepsis. Clin. Exp. Immunol. 2006, 145, 456-462. [CrossRef]

45. Xu, N.; Yao, H.P.; Sun, Z.; Chen, Z. Toll-like receptor 7 and 9 expression in peripheral blood mononuclear cells from patients with chronic hepatitis B and related hepatocellular carcinoma. Acta Pharmacol. Sin. 2008, 29, 239-244. [CrossRef]

46. Vieira, É.L.M.; Keesen, T.S.L.; Machado, P.R.; Guimarães, L.H.; Carvalho, E.M.; Dutra, W.O.; Gollob, K.J. Immunoregulatory profile of monocytes from cutaneous leishmaniasis patients and association with lesion size. Parasite Immunol. 2013, 35, 65-72. [CrossRef] [PubMed]

47. Wong, C.K.; Wong, P.T.Y.; Tam, L.S.; Li, E.K.; Chen, D.P.; Lam, C.W.K. Activation profile of Toll-like receptors of peripheral blood lymphocytes in patients with systemic lupus erythematosus. Clin. Exp. Immunol. 2010, 159, 11-22. [CrossRef] [PubMed]

48. Thiesen, S.; Janciauskiene, S.; Uronen-Hansson, H.; Agace, W.; Högerkorp, C.M.; Spee, P.; Håkansson, K.; Grip, O. CD14hi HLA-DRdim macrophages, with a resemblance to classical blood monocytes, dominate inflamed mucosa in Crohn's disease. J. Leukoc. Biol. 2014, 95, 531-541. [CrossRef] [PubMed]

49. Cros, J.; Cagnard, N.; Woollard, K.; Patey, N.; Zhang, S.Y.; Senechal, B.; Puel, A.; Biswas, S.K.; Moshous, D.; Picard, C.; et al. Human CD14dim monocytes patrol and sense nucleic acids and viruses via TLR7 and TLR8 receptors. Immunity 2010, 33, 375-386. [CrossRef]

50. Rogacev, K.S.; Seiler, S.; Zawada, A.M.; Reichart, B.; Herath, E.; Roth, D.; Ulrich, C.; Fliser, D.; Heine, G.H. CD14++CD16+ monocytes and cardiovascular outcome in patients with chronic kidney disease. Eur. Heart J. 2010, 32, 84-92. [CrossRef]

51. Rossol, M.; Kraus, S.; Pierer, M.; Baerwald, C.; Wagner, U. The CD14brightCD16+ monocyte subset is expanded in rheumatoid arthritis and promotes expansion of the Th17 cell population. Arthritis Rheum. 2012, 64, 671-677. [CrossRef] [PubMed]

52. Santos, S.S.; Carmo, A.M.; Brunialti, M.K.; Machado, F.R.; Azevedo, L.C.; Assunção, M.; Trevelin, S.C.; Cunha, F.Q.; Salomao, R. Modulation of monocytes in septic patients: Preserved phagocytic activity, increased ROS and NO generation, and decreased production of inflammatory cytokines. Intensive Care Med. Exp. 2016, 4, 5. [CrossRef] [PubMed]

53. Kaptoge, S.; Seshasai, S.R.K.; Gao, P.; Freitag, D.F.; Butterworth, A.S.; Borglykke, A.; Di Angelantonio, E.; Gudnason, V.; Rumley, A.; Lowe, G.D.O.; et al. Inflammatory cytokines and risk of coronary heart disease: New prospective study and updated meta-analysis. Eur. Heart J. 2014, 35, 578-589. [CrossRef] [PubMed]

54. Xing, J.; Liu, Y.; Chen, T. Correlations of chemokine CXCL16 and TNF- $\alpha$ with coronary atherosclerotic heart disease. Exp. Ther. Med. 2018, 15, 773-776. [CrossRef] [PubMed]

55. Davies, A.L.; Hayes, K.C.; Dekaban, G.A. Clinical correlates of elevated serum concentrations of cytokines and autoantibodies in patients with spinal cord injury. Arch. Phys. Med. Rehabil. 2007, 88, 1384-1393. [CrossRef]

56. Becher, B.; Spath, S.; Goverman, J. Cytokine networks in neuroinflammation. Nat. Rev. Immunol. 2017, 17, 49-59. [CrossRef]

57. Albillos, A.; de la Hera, A.; González, M.; Moya, J.L.; Calleja, J.L.; Monserrat, J.; Ruiz-del-Arbol, L.; Alvarez-Mon, M. Increased lipopolysaccharide binding protein in cirrhotic patients with marked immune and hemodynamic derangement. Hepatology 2003, 37, 208-217. [CrossRef]

58. Albillos, A.n.; de la Hera, A.; Reyes, E.; Monserrat, J.; Muñoz, L.; Nieto, M.; Prieto, A.; Sanz, E.; Alvarez-Mon, M. Tumour necrosis factor-alpha expression by activated monocytes and altered T-cell homeostasis in ascitic alcoholic cirrhosis: Amelioration with norfloxacin. J. Hepatol. 2004, 40, 624-631. [CrossRef]

59. Blairon, L.; Wittebole, X.; Laterre, P.F. Lipopolysaccharide-binding protein serum levels in patients with severe sepsis due to gram-positive and fungal infections. J. Infect. Dis. 2003, 187, 287-291. [CrossRef]

60. Kigerl, K.A.; Hall, J.C.E.; Wang, L.; Mo, X.; Yu, Z.; Popovich, P.G. Gut dysbiosis impairs recovery after spinal cord injury. J. Exp. Med. 2016, 213, 2603-2620. [CrossRef] 
61. Moreno-Navarrete, J.M.; Sabater, M.; Ortega, F.; Ricart, W.; Fernández-Real, J.M. Circulating zonulin, a marker of intestinal permeability, is increased in association with obesity-associated insulin resistance. PLoS ONE 2012, 7, e37160. [CrossRef] [PubMed]

62. Smecuol, E.; Sugai, E.; Niveloni, S.; Vázquez, H.; Pedreira, S.; Mazure, R.; Moreno, M.L.; Label, M.; Mauriño, E.; Fasano, A.; et al. Permeability, zonulin production, and enteropathy in dermatitis herpetiformis. Clin. Gastroenterol. Hepatol. 2005, 3, 335-341. [CrossRef]

63. Maloy, K.J.; Powrie, F. Intestinal homeostasis and its breakdown in inflammatory bowel disease. Nature 2011, 474, 298-306. [CrossRef] [PubMed]

64. Oropallo, M.A.; Held, K.S.; Goenka, R.; Ahmad, S.A.; O’Neill, P.J.; Steward, O.; Lane, T.E.; Cancro, M.P. Chronic spinal cord injury impairs primary antibody responses but spares existing humoral immunity in mice. J. Immunol. 2012, 188, 5257-5266. [CrossRef] [PubMed]

65. Cardenas, D.D.; Hoffman, J.M.; Kirshblum, S.; McKinley, W. Etiology and incidence of rehospitalization after traumatic spinal cord injury: A multicenter analysis11No commercial party having a direct financial interest in the results of the research supporting this article has or will confer a benefit upon the author(s) or upon any organization with which the author(s) is/are associated Arch. Phys. Med. Rehabil. 2004, 85, 1757-1763. [CrossRef]

66. De Vivo, M.J.; Stuart Krause, J.; Lammertse, D.P. Recent trends in mortality and causes of death among persons with spinal cord injury. Arch. Phys. Med. Rehabil. 1999, 80, 1411-1419. [CrossRef]

67. Anand, R.J.; Kohler, J.W.; Cavallo, J.A.; Li, J.; Dubowski, T.; Hackam, D.J. Toll-like receptor 4 plays a role in macrophage phagocytosis during peritoneal sepsis. J. Pediatr. Surg. 2007, 42, 927-933. [CrossRef]

68. Lam, T.D.; Lammers, S.; Munoz, C.; Tamayo, A.; Spence, J.D. Diabetes, intracranial stenosis and microemboli in asymptomatic carotid stenosis. Can. J. Neurol. Sci. 2013, 40, 177-181. [CrossRef]

69. Ghattas, A.; Griffiths, H.R.; Devitt, A.; Lip, G.Y.H.; Shantsila, E. Monocytes in coronary artery disease and atherosclerosis. J. Am. Coll. Cardiol. 2013, 62, 1541-1551. [CrossRef]

70. Lee, B.C.; Lee, J. Cellular and molecular players in adipose tissue inflammation in the development of obesity-induced insulin resistance. Biochim. Biophys. Acta 2014, 1842, 446-462. [CrossRef]

71. Biering-Sørensen, F.; Charlifue, S.; DeVivo, M.; Noonan, V.; Post, M.; Stripling, T.; Wing, P. International spinal cord injury data sets. Spinal Cord 2006, 44, 530-534. [CrossRef] [PubMed]

72. Kirshblum, S.C.; Burns, S.P.; Biering-Sorensen, F.; Donovan, W.; Graves, D.E.; Jha, A.; Johansen, M.; Jones, L.; Krassioukov, A.; Mulcahey, M.J.; et al. International standards for neurological classification of spinal cord injury (revised 2011). J. Spinal Cord Med. 2011, 34, 535-546. [CrossRef] [PubMed] 